\title{
НОВЫЕ ДАННЫЕ ПО МИНЕРАЛОГИИ ЗОЛОТОКВАРЦЕВОГО МЕСТОРОЖДЕНИЯ МАЙСКОГО (СЕВЕРНАЯ КАРЕЛИЯ)
}

\author{
Калинин А.А., Карпов С.М., Калачева А.Б., Савченко Е.Э. \\ Геологический институт КНЦ РАН, Anamumb, kalinin@geoksc.apatity.ru
}

Жильное поле Майское расположено в центральной части Куолаярвинской зоны в верхнем течении р. Вуоснайоки, приблизительно в 1 километре к югу от границы Республики Карелия и Мурманской области. Месторождение образовано двумя жильными зонами (жилы \#1 и \#40), приуроченными к двум параллельным тектоническим нарушениям северо-северо-восточного простирания на расстоянии около 250 м друг от друга. Вмещающие породы - метабазальты апаярвинской свиты людиковия, силлы и дайки габбродолеритов, силлы габбро-пироксенитов. Мощность жил - первые метры, жильные зоны прослежены по простиранию на 1600-1700 м. Распределено золото неравномерно, в пределах жил оконтурены рудные столбы длиной 110 м в жиле \#1 и 80 м в жиле \#40, содержание золота в рудных столбах составляет 13.1 и 10.5 г/т соответственно [6].

Ранее проведенные на месторождении исследования рудной минерализации жил [1-6] показали, что сульфиды и самородные металлы составляют менее 1 \% объема жильной массы. Текстура минерализации вкрапленная, реже прожилково-вкрапленная, гнездовая. Прожилки по мощности не превышают 1 см и по протяженности 10-20 см. Гнезда сульфидов в зальбандах жил могут достигать нескольких сантиметров. В составе минерализации преобладает халькопирит, присутствуют также (в порядке распространенности): пирротин, сфалерит, галенит, пирит, самородное золото. Второстепенные и редкие минералы - магнетит, марказит, кобальтин, макинавит, борнит, кубанит, кобальтовая разновидность пентландита, алтаит, цумоит, теллуровисмутит, клаусталит, галеноклаусталит, костибит, клокманит, гессит, гринокит, тетрадимит, теллуриды никеля, теллуриды золота, висмутин, серебро самородное, арсенопирит, вавржинит, ковеллин, зигенит, глаукодот, штютцит.

Месторождение Майское в последние три года прошлого столетия отрабатывалось артелью старателей «Вуосна», был добыт 51 кг золота [2], но затем заброшено, карьер затоплен. В ходе полевых работ 2016 г. из заброшенного рудного склада месторождения для минералогических исследований нами отобраны образцы кварцевых жил с сульфидной минерализацией, а из хвостов обогащения взята шлиховая проба песков.

Сульфидная минерализация в аншлифах жильного материала карбонат-кварцевого состава, отобранного на рудном складе, по минеральному составу и текстуре оруденения близка к описанной для жил месторождения в литературе [1-6]. Аншлифы были исследованы на сканирующем микроскопе Leo-1450 с предварительной оценкой состава минералов на энергодисперсионном спектрометре Bruker XFlash-5010 методом бесстандартного анализа при помощи программного обеспечения QUANTAX 200 (авторы глубоко благодарны А.А. Тележкину, выполнившему часть исследований минерализации на электронном микроскопе).

Установлено, что в халькопирите нередко присутствуют ксеноморфные включения аргентопентландита размером менее 10 мкм. Многие зерна галенита содержат микровключения алтаита и цумоита размером до 15 мкм, эти же минералы часто тяготеют к границе галенита с халькопиритом. На границе алтаита и галенита выявлены самородный теллур, штютцит и волынскит (микровыделения размером в несколько микрон). В одном случае включение теллуридов алтаита и раклиджита отмечено в пирротине.

В срастаниях с пирротином часто встречается богатый кобальтом пентландит, при этом по границе пирротина с пентландитом или с халькопиритом развиваются виоларит и зигенит. Состав виоларита отличается от стехиометрического избытком катионов (табл. 1).

Для минералогической характеристики отходов обогащения нами была отобрана проба из лежалых хвостов верхнего отстойника обогатительной установки. Глубина отбора $0-0.5$ м. Исхо-

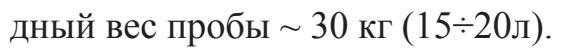


Таблица 1. Химический состав минералов Ni и Со месторождения Майского по данным микрозондового исследования на CAMECA MS-46, мас. \%.

\begin{tabular}{|c|c|c|c|c|c|c|c|c|}
\hline & 1 & 2 & 3 & 4 & 5 & 6 & 7 & 8 \\
\hline $\mathrm{Fe}$ & 3.04 & 5.17 & 3.59 & 8.38 & 14.647 & 12.86 & 27.88 & 4.36 \\
\hline $\mathrm{Co}$ & 28.10 & 24.07 & 26.84 & 8.25 & 14.637 & 16.01 & 9.17 & 33.43 \\
\hline $\mathrm{Ni}$ & 4.58 & 7.24 & 5.77 & 18.52 & 40.271 & 41.64 & 31.56 & 19.94 \\
\hline $\mathrm{Cu}$ & 0.00 & 0.00 & 0.00 & 0.09 & н/ппр. & н/опр. & н/опр. & 0.71 \\
\hline $\mathrm{As}$ & 44.69 & 44.96 & 44.75 & 44.85 & н/опр. & н/опр. & н/опр. & н/опр. \\
\hline $\mathrm{S}$ & 19.32 & 18.72 & 18.99 & 19.73 & 31.54 & 30.24 & 32.32 & 41.56 \\
\hline Сумма & 99.74 & 100.15 & 99.93 & 99.82 & 101.095 & 100.75 & 100.93 & 100.00 \\
\hline \multicolumn{7}{|c|}{ Коэффициенты кристаллохимической формулы } \\
\hline $\mathrm{Fe}$ & 0.091 & 0.156 & 0.108 & 0.247 & 0.835 & 0.709 & 3.963 & 0.241 \\
\hline $\mathrm{Co}$ & 0.795 & 0.690 & 0.766 & 0.231 & 0.791 & 0.837 & 1.235 & 1.751 \\
\hline $\mathrm{Ni}$ & 0.130 & 0.208 & 0.165 & 0.520 & 1.711 & 1.587 & 4.269 & 1.048 \\
\hline $\mathrm{Cu}$ & 0.000 & 0.000 & 0.000 & 0.002 & н/опр. & н/опр. & н/опр. & 0.034 \\
\hline $\mathrm{As}$ & 0.995 & 1.014 & 1.004 & 0.986 & н/опр. & н/опр. & н/опр. & н/опр. \\
\hline $\mathrm{S}$ & 1.005 & 0.986 & 0.996 & 1.014 & 4.000 & 4.000 & 8.000 & 4.000 \\
\hline
\end{tabular}

Примечание: 1-3 - кобальтин, 4 - герсдорфит, 5-6 - виоларит, 7 -пентландит, 8 - зигенит (по [4]). Формулы кобальтина и герсдорфита рассчитаны на сумму $\mathrm{As}+\mathrm{S}=2$, формулы виоларита и зигенита - на $\mathrm{S}=4$, пентландита - на $\mathrm{S}=8$. Минералы ряда кобальтин-герсдорфит анализировались также на $\mathrm{Ag}$ и $\mathrm{Au}$, которые не обнаружены.

В полевых условиях проба была отмучена и отмыта в лотке в озере до шлиха весом $\sim 0.89$ кг. Далее шлих был расситован на классы «+1» и «-1». Материал класса «+1» $(28,6$ г) просмотрен под бинокуляром и обнаружен 1 знак золота. Подготовка класса «-1» к полному минералогическому анализу проведена по следующей схеме:

1. Доводка пробы до получения «серого» шлиха.

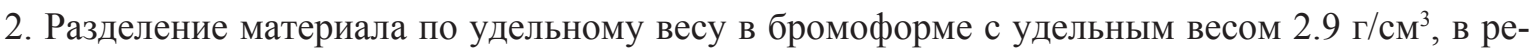
зультате чего получена тяжелая фракция весом 61.5 г (без сохранения легкой фракции).

3. Магнитная и электромагнитная сепарация тяжелой фракции магнитом Сочнева на сильноэлектромагнитную, слабоэлектромагнитную и неэлектромагнитную фракции.

4. Полуколичественный анализ тяжелой фракции под бинокуляром с диагностикой всех минералов; визуальная оценка их содержаний в каждой фракции в объемных \%. В ряде случаев для диагностики применен рентгеноструктурный анализ.

Результаты минералогического анализа тяжелой фракции в шлихе представлены в таблице 2.

Золото в шлиховой пробе хвостов ярко-желтого цвета, образует чешуйчатые, округлые и лепешкообразные зерна, редко - дендриты, тетраэдрические кристаллы. Размер золотинок преимущественно до $\sim 0.1 \div 0.2$ мм, единично встречаются чешуйки размером 1.0-1.5 мм. Частично золотинки покрыты легким красновато-бурым налетом. Микрозондовый анализ показал, что состав золота достаточно однороден и не зависит от морфологии зерен: пробность золота варьирует в пределах 900-970, постоянно присутствуют примеси серебра (первые проценты) и меди (до 0.3 мас. \%, обычно менее $0.12 \%$ ), часто - железа (до 0.13 мас. \%), другие элементы-примеси не отмечались (табл. 3).

Из тяжелой фракции шлиха были выделены немагнитный и слабоэлектромагнитный концентраты сульфидов, затем из материала фракции крупности 0.1-0.25 мм изготовлены искусственные аншлифы. «Основу» обеих фракций составили пирит и кобальтин в соотношении по объему примерно 2/1, то есть содержание кобальтина оказалось в концентратах значительно выше, чем показал минералогический анализ. Самородное золото установлено в немагнитной фракции в количестве десятков знаков, в слабоэлектромагнитной - знаки. Из нерудных минералов-оксидов в аншлифах концентратов присутствуют рутил и шеелит (содержание каждого около 1 об.\%), выявлены знаки миметита. 
Таблица 2. Результаты минералогического анализа тяжелой фракции песков из хвостов обогащения руды месторождения Майского.

\begin{tabular}{|l|l|l|l|}
\hline \multicolumn{1}{|c|}{ Минералы } & \multicolumn{1}{c|}{$\begin{array}{c}\text { Содержание, } \\
\text { об. \% }\end{array}$} & \multicolumn{1}{c|}{ Минералы } & \multicolumn{1}{c|}{ Содержание } \\
\hline гр. амфибола & 34.5 & апатит & десятки знаков \\
\hline слюда (биотит и мусковит) & 13.7 & дистен & десятки знаков \\
\hline гр. пироксена & 8.7 & титанит & десятки знаков \\
\hline гетит+лимонит & 7.4 & турмалин & знаки \\
\hline халькопирит & 4.4 & перовскит* & знаки \\
\hline магнетит & 3.3 & барит* & знаки \\
\hline гр. эпидота + гр. цоизита & 3.2 & хлорит & знаки \\
\hline ильменит & 1.4 & корунд & редкие знаки \\
\hline гематит, гематит-мартит & 1.4 & шпинель & редкие знаки \\
\hline гр. карбоната & 1.3 & арсенопирит* & редкие знаки \\
\hline рутил & 0.7 & сфалерит & редкие знаки \\
\hline пирит* & 0.5 & окислы меди & редкие знаки \\
\hline пирротин & 0.4 & клаусталит* & единичные знаки \\
\hline гр. граната & 0.1 & кобальтин* & единичные знаки \\
\hline сростки минералов & 19.0 & галенит & единичные знаки \\
\hline Сумма & 100 & молибденит* & единичные знаки \\
\hline золото & десятки знаков & куприт* & единичные знаки \\
\hline циркон & десятки знаков & сферолиты (?) & десятки знаков \\
\hline
\end{tabular}

Примечание: * - диагностика минерала подтверждена рентгеновским анализом.

Таблица 3. Химический состав самородного золота месторождения Майского, мас. \%.

\begin{tabular}{|c|c|c|c|c|c|c|c|c|c|c|c|}
\hline & 1 & 2 & 3 & 4 & 5 & 6 & 7 & 8 & 9 & 10 & 11 \\
\hline $\mathrm{Fe}$ & 0.00 & 0.00 & 0.07 & 0.00 & 0.08 & 0.08 & 0.13 & 0.11 & 0.10 & н/опр. & н/опр. \\
\hline $\mathrm{Cu}$ & 0.06 & 0.06 & 0.19 & 0.09 & 0.06 & 0.15 & 0.22 & 0.07 & 0.29 & н/опр. & н/опр. \\
\hline $\mathrm{Ag}$ & 5.53 & 5.88 & 2.86 & 6.71 & 4.09 & 5.95 & 3.52 & 3.91 & 4.84 & 3.34 & 2.97 \\
\hline $\mathrm{Au}$ & 91.10 & 90.92 & 94.30 & 90.62 & 92.96 & 92.82 & 96.76 & 95.79 & 94.67 & 97.37 & 94.74 \\
\hline Сумма & 96.69 & 96.87 & 97.43 & 97.42 & 97.19 & 99.00 & 100.62 & 99.88 & 99.90 & 100.71 & 97.70 \\
\hline \multicolumn{10}{|c|}{ Коэффициенты кристаллохимической формулы } \\
\hline $\mathrm{Fe}$ & 0.000 & 0.000 & 0.002 & 0.000 & 0.003 & 0.003 & 0.004 & 0.004 & 0.003 & н/опр. & н/опр. \\
\hline $\mathrm{Cu}$ & 0.002 & 0.002 & 0.006 & 0.003 & 0.002 & 0.004 & 0.006 & 0.002 & 0.009 & н/опр. & н/опр. \\
\hline $\mathrm{Ag}$ & 0.100 & 0.105 & 0.052 & 0.119 & 0.074 & 0.104 & 0.062 & 0.069 & 0.084 & 0.059 & 0.054 \\
\hline $\mathrm{Au}$ & 0.898 & 0.893 & 0.940 & 0.878 & 0.921 & 0.889 & 0.928 & 0.925 & 0.904 & 0.941 & 0.946 \\
\hline
\end{tabular}

В составе кобальтина доля кобальтинового минала варьирует от 65 до 80 \%, второй по значимости металл - никель (табл. 1). Кроме кобальтина установлен герсдорфит (52 \% герсдорфитового и $23 \%$ кобальтинового миналов).

В искусственном аншлифе отмечены также знаки теллуридов и селенидов. Это, в основном, пластинчатые мономинеральные выделения, только клаусталит встречен в срастаниях с халькопиритом и галенитом и содержит включения гессита. Нами установлены поубаит с разным соотношением $\mathrm{Se}$ и Tе, теллуровисмутит со значительной примесью $\mathrm{Pb}$, минерал ряда кавацулит-скиппенит, где доля скиппенитового минала 49 \% (табл. 4).

В целом, проведенные исследования показали, что на месторождении Майском значительно большую роль, чем считалось ранее, играют минералы никеля и кобальта. Впервые в составе минерализации месторождения установлены герсдорфит, кавацулит, поубаит, волынскит, виоларит, раклиджит, аргентопентландит, самородный теллур.

Работа выполнена в рамках Госзадания 0231-2015-0001. 
Таблица 4. Химический состав теллуридов. селенидов и галенита по данным микрозондового исследования на CAMECA MS-46, мас.\%.

\begin{tabular}{|c|c|c|c|c|c|c|c|}
\hline & 1 & 2 & 3 & 4 & 5 & 6 & 7 \\
\hline $\mathrm{Fe}$ & 0.18 & 0.12 & 0.10 & 0.23 & 0.08 & 0.06 & н/опр. \\
\hline $\mathrm{Pb}$ & 34.93 & 18.80 & 27.44 & 4.63 & 8.86 & 69.54 & 86.63 \\
\hline $\mathrm{Ag}$ & 0.00 & 0.00 & 0.00 & 0.00 & 0.00 & 0.45 & н/опр. \\
\hline $\mathrm{Bi}$ & 28.41 & 39.62 & 31.57 & 52.91 & 47.44 & 1.56 & н/опр. \\
\hline $\mathrm{Sb}$ & 0.33 & 0.34 & 0.00 & 0.00 & 0.00 & 0.00 & н/опр. \\
\hline $\mathrm{S}$ & 0.67 & 0.29 & 0.13 & 0.09 & 0.07 & 0.68 & 12.54 \\
\hline $\mathrm{Se}$ & 15.92 & 13.52 & 7.19 & 15.86 & 1.09 & 25.30 & 1.45 \\
\hline $\mathrm{Te}$ & 19.14 & 27.03 & 33.48 & 26.24 & 42.78 & 2.61 & н/опр. \\
\hline $\mathrm{Cумма}$ & 99.58 & 99.71 & 99.90 & 99.95 & 100.32 & 100.18 & 100.62 \\
\hline & & Коэффициенты кристаллохимической формулы & \\
\hline $\mathrm{Fe}$ & 0.043 & 0.021 & 0.020 & 0.030 & 0.013 & 0.003 & н/опр. \\
\hline $\mathrm{Pb}$ & 2.262 & 0.926 & 1.482 & 0.164 & 0.365 & 0.927 & 1.021 \\
\hline $\mathrm{Ag}$ & 0.000 & 0.000 & 0.000 & 0.000 & 0.000 & 0.011 & н/опр. \\
\hline $\mathrm{Bi}$ & 1.825 & 1.934 & 1.690 & 1.855 & 1.938 & 0.021 & н/опр. \\
\hline $\mathrm{Sb}$ & 0.036 & 0.028 & 0.000 & 0.000 & 0.000 & 0.000 & н/опр. \\
\hline $\mathrm{S}$ & 0.282 & 0.092 & 0.045 & 0.021 & 0.019 & 0.058 & 0.956 \\
\hline $\mathrm{Se}$ & 2.705 & 1.747 & 1.019 & 1.472 & 0.118 & 0.885 & 0.044 \\
\hline $\mathrm{Te}$ & 2.013 & 2.161 & 2.936 & 1.507 & 2.863 & 0.056 & н/опр. \\
\hline
\end{tabular}

Примечание: 1 - фаза $\mathrm{Pb}_{2} \mathrm{Bi}_{2}(\mathrm{~S}, \mathrm{Se})_{3} \mathrm{Te}_{2}$, коэффициенты формулы рассчитаны на $\mathrm{S}+\mathrm{Se}+\mathrm{Te}=5 ; 2-3$ - поубаит, 4 - кавацулит, 5 - теллуровисмутит, 6 - клаусталит. 7 - галенит. Коэффициенты формулы поубаита рассчитаны на $\mathrm{S}+\mathrm{Se}+\mathrm{Te}=4$, кавацулита и теллуровисмутита на $\mathrm{S}+\mathrm{Se}+\mathrm{Te}=3$, галенита и клаусталита на $\mathrm{S}+\mathrm{Se}+\mathrm{Te}=1$.

\section{Литература}

1. Гавриленко Б.В., Реженова С.А. Рудные минералы золотосодержащих кварцевожильных зон / Минеральные парагенезисы метаморфических и метасоматических пород. Апатиты: изд. Кольского филиала АН СССР. 1987. С. 58-67.

2. Гавриленко Б.В. Минерагения благородных металлов и алмазов северо-восточной части Балтийского щита. Автореф. дисс. д.г.-м.н. М. 2003. 59 С.

3. Иващенко В.И., Голубев А.И. Золото и платина Карелии: формационно-генетические типы оруденения и перспективы. Петрозаводск: Карельский научный центр РАН. 2011. 369 с.

4. Нерадовский Ю.Н. Самородное золото: типоморфизм минеральных ассоциаций. условия образования месторождений. задачи прикладных исследований / Матер. Всеросс. конф. посвященной 100 - летию Нины Васильевны Петровской. М.. ИГЕМ. 29-31 марта 2010 г. Т. II. С. 88-91.

5. Порицкий М.С., Буйко А.К., Котов Н.В., Порицкая Л.Г. Геологическая позиция и условия формирования золоторудных метасоматитов месторождения Майское (Северная Карелия) // Вестник СанктПетербургского университета. Сер. 7. Вып. 1. 1993. С. 15- 21.

6. Сафонов Ю.Г., Волков А.В., Вольфсон А.А., Генкин А.Д., Крылова Т.Л., Чугаев А.В. Золото-кварцевое месторождение Майское (Северная Карелия): геологические и минералого-геохимические особенности. вопросы генезиса // Геология рудных месторождений. 2003. Т. 45. № 5. С. 429-451. 